San Jose State University

SJSU ScholarWorks

Faculty Research, Scholarly, and Creative Activity

4-23-2020

\title{
Multiplex boundary work in innovation projects: the role of collaborative spaces for cross-functional and open innovation
}

\author{
Paula Ungureanu \\ University of Modena and Reggio Emilia \\ Carlotta Cochis \\ University of Modena and Reggio Emilia \\ Fabiola Bertolotti \\ University of Modena and Reggio Emilia \\ Elisa Mattarelli \\ San Jose State University, elisa.mattarelli@sjsu.edu \\ Anna Chiara Scapolan \\ University of Modena and Reggio Emilia
}

Follow this and additional works at: https://scholarworks.sjsu.edu/faculty_rsca

Part of the Business Administration, Management, and Operations Commons, and the Technology and Innovation Commons

\section{Recommended Citation}

Paula Ungureanu, Carlotta Cochis, Fabiola Bertolotti, Elisa Mattarelli, and Anna Chiara Scapolan.

"Multiplex boundary work in innovation projects: the role of collaborative spaces for cross-functional and open innovation" European Journal of Innovation Management (2020): 984-1010. https://doi.org/10.1108/ EJIM-11-2019-0338

This Article is brought to you for free and open access by SJSU ScholarWorks. It has been accepted for inclusion in Faculty Research, Scholarly, and Creative Activity by an authorized administrator of SJSU ScholarWorks. For more information, please contact scholarworks@sjsu.edu. 
Multiplex Boundary Work in Innovation Projects. The Role of Collaborative Spaces for Cross-functional and Open Innovation.

\author{
Ungureanu Paula*+ \\ Cochis Carlotta* \\ Bertolotti Fabiola* \\ Mattarelli Elisa** \\ Scapolan Annachiara***
}

*Department of Sciences and Methods and Engineering, University of Modena and Reggio Emilia

**Department of Management, San Jose State University

**Department of Communication and Economics, University of Modena and Reggio Emilia

${ }^{+}$Corresponding author: Via Giovanni Amendola, 2, 42122 Reggio Emilia RE

E: paula.ungureanu@unimore.it 


\section{Purpose}

This study investigates the role of collaborative spaces as organizational support for internal innovation through cross-functional teams and through open innovation with external stakeholders. In particular, the study focuses on collaborative spaces as tools for multiplex i.e., simultaneous internal and external- boundary management in open innovation projects.

\section{Design/methodology/approach}

We conducted a qualitative study in a multi-divisional organization that set up a collaborative space for collaborative product development in its headquarters. Data were collected through semi-structured interviews and participant observations.

\section{Findings}

Findings highlight the importance of the relation between expectations and experiences about the collaborative space in employees' ability to perform boundary work inside and outside the organization. While findings document an affording role of the collaborative space for expectations about hands-on open innovation (space as laboratory), they also highlight a set of collaboration constraints. Constraints are generated by discrepancies between expectations and actual collaboration experiences in the space (i.e., space as maze, cloister, showcase and silo) which slow down internal and external boundary work and generate a trade-off between the two.

\section{Originality/value}

Using the process-based perspective of boundary work, the paper connects studies on crossfunctional teaming and open innovation. It also contributes to the literature on boundary work by showing the challenges of multiplex boundary spanning with the help of boundary spaces.

Keywords: cross-functional teams, open innovation, open innovation, boundary work, collaborative spaces, boundary objects. 


\section{Introduction}

An organization's ability to innovate is often associated with the ability to cross boundaries, be they internal (i.e., by means of cross-functional innovation teams) or external (i.e., by means of open innovation projects involving external stakeholders). As organizations attempt to cross internal and external boundaries in the search for new innovation-based competitive advantages, the processes involved in generating innovative ideas, and ultimately transferring them into the market, become increasingly sophisticated and complex (Clark and Wheelwright, 1993, Thamhain, 2003, Edmondson and Harvey, 2018, Chesbrough et al., 2006). Innovation studies usually treat internal innovation and external or open innovation separately, to highlight the unique challenges and opportunities that each type of innovation entails. In particular, many works have adopted a configurational approach, highlighting opportunities and challenges of either external or internal boundary spanning, and trying to establish the characteristics that such collaborations must have to maximize innovation outcomes. For instance, conducting innovation with diverse stakeholders, such as clients, suppliers, users, is an opportunity in terms of better knowledge flows, more learning opportunities and timely, more adequate responses to the market. At the same time, it also entails risks in terms of high coordination costs, cultural and professional barriers, conflict escalation, opportunism and difficulties to converge towards a common goal (Brown and Eisenhardt, 1995, Jassawalla and Sashittal, 1999, McDonough III, 2000). From the perspective of internal innovation, participants' diversity in cross-functional teams may significantly fuel but also seriously deter innovation processes (Edmondson and Harvey, 2018, Holland et al., 2000, Lovelace et al., 2001, Nicholson et al., 2001). Risks are due to the complexity of managing multiple actors with diverse backgrounds and potentially different interests and channeling them towards the same objective which in the case of innovation situations, is often ill-defined (Tushman, 1978). 
It is noteworthy that organizations often make use of external and internal innovation simultaneously, crossing both functional and organizational boundaries in order to successfully manage their portfolio of innovation projects. However, external and internal boundary spanning for innovation have rarely been studied together, and their benefits and challenges have not been interrelated by previous works. In this work, we focus on the concept of 'boundary work' to connect the concepts of cross-functional and open innovation (Faraj and Yan, 2009, Carlile, 2004, Langley et al., 2019). By multiplex boundary work we refer to those strategies that members of organizations enact to construct, tear down and reshape differences within internal cross-functional teams and in open innovation teams simultaneously. Within an organization, professionals from marketing, sales, and R\&D may create, maintain or reconsider interprofessional and occupational differences to build new, more balanced social orders within the organization (internal boundary work) (Carlile, 2004, Bechky, 2003, Faraj and Yan, 2009). Organizations may also engage in external boundary work in order to negotiate efficiency, power, competence and identity claims with their external environments (Santos and Eisenhardt, 2005, Kellogg et al., 2006). Importantly, in line with the boundary work framework, we highlight that diversity boundaries are often managed through concrete yet creative practices and tools that are made available by the organization. The literature on creativity and innovation has underlined the fundamental role of physical proximity and shared organizational artifacts (i.e., boundary objects) in favoring boundary work in innovation processes, thanks to increased attention, familiarity, coordination, and spontaneous conversations enabled by face to face encounters and interactions (Kiesler and Cummings, 2002, Bechky, 2003, Koskinen, 2005, Nicolini et al., 2012). Collaborative spaces are physical spaces specifically designed and built to support the creativity of individuals, groups and organizations by leveraging on physical proximity (Capdevila, 2015, Oksanen and Ståhle, 2013, Garrett et al., 2017, Furnari, 2014). We are thus concerned with the strategies by which 
organizations try to enact internal and external boundary work simultaneously, and we inquire about the tools and strategies that allow them to do so, focusing on the role of collaborative spaces as support tools for internal and external innovation,

To this purpose, we conducted a qualitative study in a multi-divisional organization in the food industry that created a collaborative space in its headquarters in order to foster collaboration on both internal and external innovation projects. We studied the impact of the collaborative space on employees' ability to simultaneously perform internal and external boundary work by comparing their expectations about the space with actual experiences of it. Findings show that collaborative spaces are expected to have revolutionary effects on how employees collaborate across organizational functions and with external stakeholders such as clients, suppliers, consumers, and the public press. In particular, by serving as a laboratory (i.e., being plastic, informal and central) the space is expected to tear down internal and external boundaries, affording free knowledge exchanges and an improvement in creativity and knowledge exchange quality. Although we confirm that a collaborative space may afford the alignment between participants' initial expectations and actual experiences, we also show that unexpected constraints can emerge and generate a trade-off between participants' ability to perform internal and external boundary work. Specifically, increasing diversity in collaborations makes boundary work more effortful and resource-demanding, such that when employees focus on internal boundary work, they may become unable to perform well also in external boundary work, and vice versa. In addition to connecting studies on cross-functional teaming and open innovation through the boundary work perspective, we propose the term of multiplex (internal-external) boundary work and describe its mechanisms, including the paramount role played by materiality and the role of (perceived) boundary configurations. Drawing on our theoretical contributions, we also discuss implications for how organizations may design feasible collaborative spaces for open innovation. 


\section{Theoretical Framework}

\section{Crossing internal and external boundaries to innovate from cross-functional teams to open innovation}

\section{Internal innovation: cross-functional teams for product development}

Ancona and Caldwell (1992) define a cross-functional product development team as a collection of members of different departments and disciplines brought together under the same responsibility and given the charge not only to make product development decisions but also to provide support for them throughout the organization. In a review, Holland and colleagues (2000) identify a wide range of positive and negative aspects attributed to cross-functional teams for product development. Among the first, the authors mention improved ability to handle complexity, better quality of exchanged information, higher development speed, greater opportunities for organizational learning and employee motivation and creativity. On the other hand, the associated dangers are conflicting organizational and personal goals, competition for resources, overlapping and/or unclear responsibilities, ambiguity over priorities and lack of cooperation. Research on cross-functional teams has largely adopted a configurational perspective - i.e., investigated the team compositions and conditions that maximize advantages and minimize disadvantages for innovation outcomes. According to existing studies, a characteristic responsible for both identified opportunities and disadvantages is participants' diversity - i.e., the personal, organizational and professional differences that members bring along in a cross-functional team. On the one hand, diversity is shown to increase creativity in the development process. Brown and Eisenhardt (1995) showed that an increase in the amount and variety of information available to design products allows team members to understand the design process more deeply and quickly, such that the overall project performance is improved.

On the other hand, however, studies suggest that diversity of viewpoints may also generate and escalate conflict at the team level (Holland et al., 2000, Dahlin et al., 2005, Lovelace et al., 
2001). Another frequently mentioned characteristic of cross-functional teams is their being assigned to development projects on a temporary basis. This characteristic may push members to act creatively and overcome rigid roles and organizational structures. At the same time, it also risks to increase coordination and negotiation costs at the team level. Moreover, crossfunctional teams often face high-performance expectations and aspirational goals such as compressing development times, creating new knowledge and enhancing organizational learning. While such expectations may stimulate members to top perform, they may also generate stress and conflict, including scapegoating at the team level (Dahlin et al., 2005, Lovelace et al., 2001).

\section{External boundary work: open innovation with external stakeholders}

As sources of innovation become more diverse and distributed throughout industries and geographic regions, firms shift the focus beyond their own organizational boundaries, often engaging in collaboration with external stakeholders such as other organizations, clients, consumers, NGOs and other societal actors to create joint intellectual property (West and Bogers, 2014, Greer and Lei, 2012, Baldwin and Von Hippel, 2011, Chesbrough, 2003a). Research has discussed open or collaborative innovation as a paradigm according to which infusing external ideas in product development can provide significant competitive advantage for an organization, especially if aligned with the organization's business model (Chesbrough, 2003b, Zott et al., 2011, West and Bogers, 2014). Just as in the case of cross-functional teams, the literature on open innovation has also taken a configurational approach, focusing on the type of actors taking part and the form of collaboration taking place, the drivers for participating in open innovation projects, and the characteristics of innovation outcomes (West and Bogers, 2014). For instance, while most research still refers to dyadic collaborations (Bercovitz and Feldman, 2007, Li and Vanhaverbeke, 2009), attention is shifting to innovation networks and innovation communities. These latter are characterized by the presence of a large 
variety of stakeholders holding different background and abilities to participate to the development process, as well as different incentives and levels of motivation(Baldwin and Von Hippel, 2011). Also, the way partners select each other shapes the type of collaboration taking place later on and the innovation outcomes obtained (Emden et al., 2006, Slowinski and Sagal, 2010). Echoing the findings in the cross-functional team literature, recent contributions identify also a list of disadvantages, such as the difficulty of establishing overarching goals, conflict escalations due to diverse backgrounds, high coordination costs due to heterogeneity in capabilities and motivations, and the difficulty in incorporating external ideas into a single company's product and services (Baldwin and Von Hippel, 2011, Greer and Lei, 2012, West and Bogers, 2014, Lifshitz-Assaf, 2018). Other studies mention strategic disadvantages at the firm level, including the trade-off between resources donated to project partners and results obtained, and loss of strategic control, information and competitive advantage at the organizational level (Stam, 2009, Spaeth et al., 2010).

\section{Performing boundary work in cross-functional teams and open innovation}

Summarizing, despite adopting similar perspectives, internal and external boundary work for innovation are often treated separately in the innovation literature, as cross-functional teams, and open innovation, respectively. While the first stream of research strives to identify the characteristics of cross-functional teams to be associated with successful product innovation and to a lesser extent, with innovation processes in such teams- studies on open innovation often adopt perspectives grounded in strategy of the firm to explain the contingencies of successful collaboration of organizations with their environments. Interestingly, a few studies suggest that configurations of diversity -be they internal or external- do not explain by themselves innovation performance, such that more attention must be given to strategies of boundary management -i.e., strategies enacted by members of a team to obtain information and resources from diverse sources, to initiate interactions with, and respond to communications 
from, other parts of the organization, despite differences. For instance, Boscherini and colleagues (2010) talk about the strategies that firms may employ to identify, plan, and manage a pilot project for open innovation and Koskinen (2005) talks about the ability to recognize and correctly use boundary objects to overcome barriers within and between organizations pursuing innovation. However, studies on boundary work conducted in other settings suggest that there is no 'correct' way to use a boundary object, and that boundary objects are often created and re-created ad-hoc, rather than waiting to be planned or recognized by project members. For instance, it has been shown that individuals can leverage diversity in highly creative ways, acting as resourceful strategists that simultaneously defend and tear down functional boundaries (Bechky, 2003, Carlile, 2004, Carlile, 2002, Kellogg et al., 2006, Majchrzak et al., 2012, Edmondson and Harvey, 2018). Therefore, focusing on transitions between breaking and defending boundaries, or on interplays between setting up and interpreting boundary objects may further help understand the dynamics of collaborative innovation.

It is also noteworthy that more boundary management strategies can be enacted simultaneously with the same interaction partner or with multiple partners. However, not only there are few studies on how organizations simultaneously leverage external and internal boundaries for innovation, but indications provided by these studies have been contrasting so far. Holland and colleagues (2000) suggested that organizations that are successful in internal innovation thanks to cross-functional teams may also be more inclined to engage in open innovation with their external environment. For instance, Allen (1970) discovered that successful R\&D teams benefited from 'gatekeepers' who communicated frequently with people outside the team, while Ancona and Caldwell (1992) showed that high-performing development teams carried out more external activity to secure resources and information needed internally. By contrast, other studies suggested that internal and open innovation represent different paradigms, each having different design and architecture costs and requiring different patterns of team 
communication, such that when an organization tries to implement both, the open model is likely to replace the internal model, increasing complexity at the organizational level (Baldwin and Von Hippel, 2011).

All in all, given the limited understanding of how members of an organization leverage simultaneously differences within and across organizations in order to perform collaborative development, we further turn our attention to the literature on boundary work, and in particular, to the role of collaborative spaces as organizational support tools for boundary work.

\section{The Role of Collaborative Spaces for Boundary Work and Innovation}

There is increasing evidence that the success of cross-functional innovation teams depends on the organizations' ability to provide support and facilitation for members' attempts to reconcile cross-functional differences. This can happen, for instance, by creating dedicated organizational roles and structures, such as appointing project brokers and ensuring an appropriate climate for innovation and learning (Donnellon, 1993, Dougherty, 1993, McDonough III et al., 2001). Recently, there has been increased attention to collaborative spaces interpreted as organizational structures intended to facilitate cross-functional work (Cabral and Van Winden, 2016, Garrett et al., 2017, De Vaujany et al., 2019, Ungureanu et al., 2018c). The creation of such spaces within organizations is based on the assumption that faceto-face contact has a positive impact on the propensity of individuals with different backgrounds to interact and exchange ideas (Oksanen and Ståhle, 2013), thus favoring the development of creative collaborative communities (Garrett et al., 2017, Ungureanu et al., 2018b). It is interesting to notice that collaborative spaces can have a double function: allow organizations to conduct cross-functional internal innovation, and, at the same time, provide the context for open innovation with external stakeholders (Ungureanu et al., 2019, Ungureanu et al., 2018c). In cross-functional teams, proximity increases the chances of spontaneous knowledge exchange, fast decision making, timely responses to the needs of others, creativity 
and market success. Isolation and geographical distribution, by contrast, worsen the problems of separate cultures, jargon and perceived personality differences, decreases creativity and worsens innovation outcomes (Ambos et al., 2016, Martin and Salomon, 2003, Meyer et al., 2011). Regarding open innovation, studies on 'third places' such as co-working and makers' spaces show how actors from different organizations are encouraged to pursue creative outcomes thanks to absence of hierarchical structures, flexibility and freedom, while also enjoying some of the typical advantages of the organizational life like access to new networks for business opportunities and participation to the social life of a community (Spinuzzi, 2012, Howell and Bingham, 2019, Gandini, 2015).

As highlighted above, also existing studies on collaborative spaces have adopted a configurational approach, correlating physical features and affordances for innovation (i.e., 'informality'). However, the same studies suggest that it is not easy to identify a single explanatory theory about the role of organizational space in innovation behavior and that practical attempts to control informal interaction in organizations through the design of the workspace are marked by contradictory findings and unintended consequences (Fayard and Weeks, 2007, Pearce et al., 2016, Ungureanu et al., 2018a). To explain the contradictory results of such studies, researchers highlight the relationship between organizational space and organizational boundaries and call for additional research on collaborative spaces as boundary spaces. For instance, a compartmented but modular space may, on the one hand, protect participants and allow them to have open meetings in the idea generation phase of a development project but also to find concentration and privacy in subsequent phases of idea elaboration and refinement (Elsbach and Pratt, 2007).

Specifically, it has been argued that the materiality of spaces is essential for organizational members to accomplish common projects because it co-locates them in the same dimension, encourages them to explore each other and enables them to create a common tangible ground 
through which differences can be more efficiently mitigated (Elsbach and Pratt, 2007, Van Marrewijk and Yanow, 2010). Yet, physical spaces can also act as barriers whenever participants feel threatened inside a cross-functional project. It results that although the material dimension of spaces matters, what we usually refer to as materiality does not derive from the use of spaces itself, but from the entanglement between material artifacts and social action -the myriad of interpretations, intentions, goals and expectations that individuals project towards such spaces as well as towards each other (Leonardi, 2012, Carlile et al., 2013). For instance, any layout of an organizational space (walls, doors, furniture, colors, and sizes) will combine in unique ways with the symbolical, affective, ethical or ideological connotations given to them by those who inhabit the space more or less stably, becoming live tools for envisioning innovative scenarios. It is thus necessary to pay closer attention to the uses of boundary spaces and the functions they afford for cross-functional and open innovation. In addition, closer attention to the relationship between space use and boundary work is necessary in order to explain how they come about and interplay to influence innovation outcomes (Edmondson and Harvey, 2018).

In conclusion, many studies explore the configurational properties of a team (who) and the configurational properties of a space (how) and their impact on innovation outcomes (what). To expand this literature, we propose a switch from features to processes. A focus on boundary work processes not only can help us understand how internal and external boundaries are managed jointly in innovation projects, but also contribute to the call in the boundary work literature about a deeper understanding of multiple boundary spanning (Langley et al., 2019). 


\section{Data and Methods}

\section{Context: Foodcorp's Collaborative Space}

We draw on empirical evidence from a six-months field study to explore the role of a collaborative space set up inside an organization aiming to promote internal (cross-functional teams) and external (i.e., open innovation teams) projects for product innovation.

The context studied is a multinational group in the food industry, fictitiously labelled. Founded in 1870s in Italy as a food shop, today FoodCorp is a world leader in the food market in different segments, with estimated 3 billion turnover and approximately 8,000 employees across the world, counting more than 25 production sites and exporting to over 100 countries worldwide. As a benchmark in production and distribution processes, FoodCorp also invests in continuous innovation. Among FoodCorp's strategic goals are those of pursuing product and process innovation for expanding its market share, reducing environmental impact, and promoting healthy lifestyles.

FoodCorp set up in 2015 a collaborative space within its headquarters with the goal to propose less constrained collaborations between organizational functions, and between headquarters and local branches, in addition to increasing interaction with external stakeholders. The collaborative space (from now on, CS) was designed and managed by the Research and Development Department of the Group, and commonly hosted work-teams composed of employees from company's multiple departments and offices, clients, suppliers, consumers, consultants, opinion leaders, bloggers, journalists, master's students and researchers. Each project team was called upon to solve a need or to optimize a product, or a process, within projects that lasted from several weeks to more than a year. The CS was created following a 'smart urban' style. It occupied a former factory building that was owned and operated by FoodCorp. It was set up as an open space with minimalist design furnishings from recycled materials. Given the focus on interactive and hands-on collaborative sessions, the furnishings 
of the space were for the most part mobile, so that the actors involved could change the space layout according to emergent needs at each session of use. In 2016, more than 200 people from different countries (Zimbabwe, UK, Congo, Canada, Colombia, Italy) and the most varied skills, from communication to marketing through design and sales, participated in innovationrelated projects within the CS. FoodCorp is currently also trying to test the new approach to innovation in other local offices in Sweden and the United States.

\section{Research design and data collection: A grounded theory approach}

We conducted a 6 months field study in FoodCorp and we defined a qualitative case study in accordance with the grounded theory approach which implies iterations between data collection, data analysis and theorizing (Strauss \& Corbin, 1998).

We collected data continuously in the time span between February 2018 and June 2018, and sporadically in the period from June 2018 to September 2019 (i.e., we entered and exited the contexts 5 times for various research purposes such as new rounds of thematic exploration, confirmatory analyses of the coding scheme, managers' follow-up requests and verification of the final model with the CS managers and users). We employed multiple data sources to support our theory building process, specifically, semi-structured interviews and participant observations. We collected more than 60 hours of observations in the field and we conducted 31 semi-structured interviews.

Semi-structured interviews: The semi-structured interviews were conducted face-to-face and have an average duration of 110 minutes. The interviews were organized around a set of openended questions following an interview protocol that focused on issues related to expectations, perceptions, management and use practices of the CS. We interviewed 24 persons internal to the organization, coming from 6 different functional areas and 7 externals, including actors from other organization and master students. $58 \%$ of informants were females. All interviews 
were fully recorded and transcribed. Table 1 summarizes keys characteristics of the informants involved in the data collection.

-insert Table 1 about here-

According to the grounded theory approach, the interview protocol was continually adjusted during the research. Simple open questions included: "Describe innovation projects in FoodCorp"; "Describe the collaborative space"; "Why and when do you use the collaborative space?"; "Describe an innovation project in which you participated in the collaborative space". Some questions entering into more details, guided from respondent's answers, included: "Who do you collaborate with more often in the collaborative space, and why?"; "What are some collaboration-for-innovation challenges you faced inside and outside the CS?; "How do you manage differences during innovation projects and how satisfied are you about what you accomplished during CS sessions?"; "Can you describe a meaningful innovation project in which team differences were managed with satisfying/unsatisfying results?”.

Participant observation: During the in-residence period inside FoodCorp we also conducted participant observations of many occasions. We observed our first meetings with the CS manager, and 8 episodes of FoodCorp's work life (3 observations of open work spaces in FoodCorp, 2 observations of the meeting rooms adjacent to the CS, 1 observation of a guided tour to the pilot $\mathrm{R} \& \mathrm{D}$ production plant, 2 observations of $\mathrm{R} \& \mathrm{D}$ offices). Moreover, we conducted 5 observations of the CS: 3 observations of collaborative sessions organized in the CS, 2 observation episodes of external stakeholders (i.e., masters' students) working in the CS on a project assigned by FoodCorp. Finally, we also conducted observations during feedback and follow-up sessions with our informants at the end of the project. About $80 \%$ of the observations were conducted by the first two authors who checked field notes and discussed 
them after each observation episode. The remaining was conducted by a research assistant who worked under the supervision of the first author.

\section{Data Analysis}

We analyzed our data following the grounded theory methodology (Strauss and Corbin, 1998).

In the beginning, we read independently the transcripts to identify original terms and phenomena in the data, group them into categories, and generate first order (informant centric) concepts. We regularly met to analyze sets of two or three transcripts, discuss our independent coding, and agree on first-order concepts. Then, by separately clustering convergent categories at a higher level of abstraction, we looked for relationships among first-order concepts to identify theoretical categories (i.e., second-order themes). Both in this phase and in the following phase when we started looking for aggregate theoretical dimensions, we met frequently to discuss about the themes we had identified independently and to solve disagreements. Figure 1 provides a representation of the three levels in our data structure.

-insert Figure 1 about here-

Later, we connected the previously identified categories following a process-oriented perspective (Langley et al., 2019). After further refinement, we organized the model in three stages explaining how the organization manages internal and external boundaries with the help of a collaborative space. We used the Nvivo software to perform all the stages of coding. To validate our model, we organized two meetings, one the CS managers and one with the CS managers and 8 informants who agreed to give us feedback on the model. 


\section{Findings}

We present a grounded model of the strategies through which an organization engages in simultaneous internal (cross-functional) and external (open innovation) boundary work in product innovation projects with the help of an organizational collaborative space. The model identifies three dimensions that concur in explaining the use of the CS for innovation boundary work within FoodCorp: 1) collaborative goals associated with internal and open innovation; 2) expected impact of CS on internal-external boundary work; and 3) experienced internalexternal boundary work in the CS. For clarity, we anticipate the grounded model in Figure 2, and we proceed by describing each category in the model and their relationships. In addition to the interview excerpts presented in the text, we also provide an appendix with further evidence (i.e., data excerpts) for each of the categories in our grounded model.

insert Figure 2 about here-

\section{Collaborative goals associated with internal and external innovation:}

\section{Collaboration goals in the CS}

We found that FoodCorp felt a pressing need to overcome pre-existing processes for product development by trying to "de-structure the product innovation processes in place", as many informants explained to us. The product development processes in FoodCorp were traditionally characterized by high levels of reliability and obsessive attention to product quality, which also implied long times to market and high costs of internal and external coordination. The highly articulated approach to innovation was a 'phase and gate model'. Specifically, FoodCorp divided the development process into neatly distinct stages such as scouting, design, testing and validation, industrialization and launch, separated by decision points (i.e., gates). While such organization allowed for both efficient specialization and collaboration, it also left organizational members unsatisfied for several reasons. First, while solutions were ultimately 
robust, they took a long time to reach the market, lacked flexibility and often reflected internal struggles and concerns more than customer needs and changes in the market. Additionally, many informants explained that while the phase and gate process had been used over time to develop some of the company's 'greatest hits', it also risked to turn project interactions into formalized routines, undermining the creativity of the single participants and the overall innovativeness of the projects -something that many of our informants referred to as 'product development bureaucracy'. Therefore, we identified a pervasive rhetoric regarding the need to embrace change in the development process which was spread at different hierarchical levels and across organizational units, from the R\&D function to marketing, sales, operations and HR departments. The collaborative space aimed at de-structuring product development projects. It was used to implement collaboration for innovation using the alternative approach of design thinking, based on participative and iterative product development. As the manager of the CS explained to us, the CS was designed to pursue two interrelated goals: innovation through internal co-generation and innovation through co-creation with external stakeholders, as follows.

\section{Product innovation through internal boundary work: co-generation}

Given that FoodCorp had always manifested specific attention to cross-functional interaction for product development, teams involved in phase and gate development projects were traditionally composed of experts coming from different departments. Not only did team members watch over their own concerns, but they also tried to bring their own expertise in the project and worked with the others to ensure that the final product met all concerns and requirements. However, as informants explained, the degree of involvement of each function was significantly different across phases, such that the R\&D had a dominant role over the first phases, and the other functions came in later in the process, often for validation purposes. As the manager of the CS explained to us, the new design thinking method was considered a 
'democratic' approach capable of better encouraging all members of the organization -thus, not only R\&D experts- to share ideas and visions about new product development from the earliest stages of a project, this way mobilizing all company resources and exploiting different knowledge and expertise across the organization. As explained to us, the ultimate goal was to implement a co-generation approach to product development. By being person-centric, the method aimed at unravelling each person's ability to develop original ideas, encouraging them to behave as both creators and recipients of a development project (for further examples see Appendix) (Brown, 2008).

It is noteworthy that the design thinking approach was not meant to replace the existing phase and gate innovation process but to provide an additional tool for deeper, wider and richer processes of idea generation. The CS pursued de-structuration of formal collaboration, encouraging informal, continuous and creative knowledge exchanges. In addition, design thinking sessions were intended not only for disruptive innovation regarding new product development but also for improving existing products or solving existing problems to ensure more efficient product-to-market processes.

"Let's say that we see the design thinking sessions in the CS as the beginning of everything, we tend to use them in projects that have not entered the phase and gate process yet, the goal is to create the next innovation platforms, for example, the protein platform, it's not an R\&D project yet, it hasn't entered phase and gate, so this is the moment to push for co-generation (... ) the method is more about pure innovation, let's say, pulling out the most brilliant ideas out there, and giving the opportunity to everybody in the organization to contribute, not just to $R \& D$ technicians" (Informant 15, R\&D)

To ensure co-generation, the approach prioritized the variety in the team, trying to make sure that the greatest number of viewpoints and expertise was represented. Internal collaboration sessions were often promoted by the $R \& D$ unit which launched a challenge to other organizational functions such as marketing, HR, quality, digital transformations and sales, and organized the working sessions with those who answered their call.

Product innovation through external boundary work: co-creation 
Collaborations between internal organizational departments and external stakeholders, like retail customers, consumers, suppliers, consultants, researchers, and students, were the second type of collaboration fostered by the CS. Similar to the internal collaboration projects, external projects were set up with the main goal of fostering innovation. However, external projects organized in the CS tried to pursue co-creation with various stakeholders. This implied that outsiders were no longer seen as mere validators of the products developed internally, but as active contributors to their generation, for instance by providing input based on their own needs and knowledge of the market, and by working with FoodCorp side by side to develop integrated, and mutually feasible solutions for the market. For these reasons, informants referred to this type of innovation as 'embedded' and defined it as the most challenging but also as the most rewarding initiative of the organization. In practical terms, external collaboration usually implied the mobilization of an internal promoter (in informants' words, 'sponsor') who launched a challenge to both internal and external actors and coordinated with the CS management to plan and organize design thinking sessions for the project.

"The embedded project is characterized by the fact that involves a team of external people, let's call them consultants, that are invited and work together with an internal team on a project that is designed and assigned to us by the organization. For instance, now we are working with $R \& D$ people and experts in other five functional areas. At the end of the day the goal is to reach a high degree of idea integration as the project moves forward" (Informant 2, external user)

\section{Expected impact of collaborative space on internal and external boundary work}

In terms of expectations about the role of the CS on internal and external boundary work, we refer not only to the objective for which the CS was designed and built by the organization, but also to the desiderata that each user had about how the CS would have contributed to their work within the organization, and to the behaviors that they expected from the other participants in the development process. From such standpoint, we found that the physical characteristics of the CS were stably and recurrently associated with users' expectations about their collaboration, as well as with the innovation outcomes that they hoped to generate. 


\section{Generalized expectations: CS as laboratory for internal and external boundary work}

In line with the declared purposes of FoodCorp's CS, the generalized expectations were that the space served as a melting pot - or 'boundary breaker', as some informants termed it gathering contributions from people with different backgrounds, goals and interests, and allowing them to express freely and to build on each other's inputs without the pressure of formal constraints. The informants often referred to the CS as a laboratory with three distinct features: plasticity, informality, and centrality and explained how insiders and outsiders could have taken advantage of these features to engage in radically new ways of collaboration for innovation. Such new approach that informants at times explicitly referred to using the term 'open innovation' (Chesbrough et al., 2006) was expected to tear down all organizational boundaries, both internal and external, to achieve free knowledge exchanges and joint decisionmaking during development projects. As shown also by the following field note excerpt, informants perceived the CS as a melting pot where to take full immersions into design thinking sessions, leaving differences behind and enjoying the discovery of each other's different viewpoints, while also having the possibility to create something new, through artifacts, prototypes, or physical models.

"This space is designed as something radically different because it's light, fun, informal, it's egalitarian. When you enter a design thinking session, you leave your organizational role at the door and enter as a person genuinely interested in what the others have to say. It is meant to be inclusive and avoid judging according to functional stereotypes, the ultimate purpose is to avoid those types of discussions among us that often end up being a bit defensive, conflicting and at the end of the day kind of unproductive" (Informant $8, R \& D$ )

First, the CS was located in an area of the central building that belonged to the R\&D function.

The area was high traffic and situated not far away from the cafeteria yet somewhat separate from the offices and the adjacent production plant. According to informants, this situation expressed CS's openness towards the outside and its potential to stimulate creativity in everyone, immersing them in a "different environment from the traditional office", as many 
informants termed it, while also giving them the opportunity to "reach the venue within minutes”.

Second, the CS was seen as plastic because it was designed by the organization as a creativity temple that adapted to the changing needs of each person who used or visited the area. For instance, the space was easily transformable from closed offices to semicircle working stations and to open areas for presentations (see also interview excerpts in appendix).

Third, the CS was perceived as highly informal - i.e., bright, colorful, comfortable and friendly in its layout and furnishings. Our informants expected such features to allow free knowledge exchanges as well as more participated and less hierarchical decision making about the project, leading to faster development processes and solving, this way, a main problem of the traditional phase and gate process. These features are summarized in the following excerpt:

"[...] the fact that it's modular can have many advantages, not only the area could be modified according to the specific needs of each group, but it can be both an active idea lab and a space for reflection where you can finally stop running and start thinking. Importantly, an open and easy area allows you to engage in spontaneous talks with colleagues, you know, just have some plain conversation, beyond roles, hierarchies and stuff like that, just bringing people together freely. Or it can be just a huge open space where you can make big things happen. To me it's a place where things will happen, where you can cook new recipes, try things, experiment." (Informant 5, $R \& D$ )

It is thus interesting to notice that, despite the different collaboration goals that FoodCorp had set internally and externally, the CS was seen as a laboratory capable of equally tearing down internal and external boundaries, encouraging co-creation, fostering joint decision making and creating value both inside and outside the organization. (see also appendix)

\section{Expected collaborative behaviors in the CS}

We found that the generalized expectations mentioned above led to the formation of more specific expectations about participants' collaborative behaviors in the CS. Specifically, in order for the space to actually serve as a laboratory for free knowledge exchanges and joint 
decision making with internal and external actors (i.e., centrality, plasticity and informality), people using it were expected to follow a set of behavioral rules, described next.

Maintain constant participation in CS activities. First, informants agreed that the design thinking activities promoted in the CS are effective if the team created upfront is heterogeneous and preserves its heterogeneity throughout the development project. This implies that team members, be they internal or external to the organization, must actively participate to all the project meetings and sessions organized in the space (especially when the project develops across multiple sessions).

Dedicate full attention to CS activities (no use of computer, smartphone, etc.). The analysis of the interviews shows that the CS is experienced by the employees of FoodCorp as an 'analogical space'. In fact, employees reported feeling often overloaded by the use of the collaborative technologies available in the company (e-mail, instant messaging, call, videoconference). They explained that taking some time off from the workstation would have helped them reduce stress and work overload, and re-appropriate of some time to think out of the box. As a consequence, the CS management encouraged participants to enter the CS without their laptops and smartphones, and avoid working simultaneously on other projects, so that there would be no interruptions during the sessions nor other negative consequences such as fragmentation of the teamwork.

Always come prepared and actively contribute to CS activities. According to the participants, for a successful session in the CS it is essential that all participants, be they members of the organization or external members, come in prepared and give an active contribution to the activities in the project. The following excerpt exemplifies the expected behaviors mentioned above:

"Here in the CS we intend to stay analogic, just put away all the distractions, like answering-emails and being-on-the-phone, thing that everybody is doing during meetings. We don't want that here, we want people to come in and participate with all their senses, having body and mind present in the same place at the same time 
(...) Also, for projects to evolve, there must be commitment and continuity, some motivation to see the group's ideas grow (...)" (Informant 11, CS Manager, R\&D)

\section{Experienced internal and external boundary work in the collaborative space}

Experiences about boundary work refer to the way people actually use the CS to shape and shift their work boundaries, both internally and externally. We compared actual experiences with the goals and the expectations described above. To this purpose, we distinguished between the following sub-categories: experienced collaborative behaviors in the CS, experienced affordances and constraints for collaboration of the CS, and experienced internal-external boundary work in the CS, each presented in the following sections.

\section{Experienced collaborative behaviors in the CS}

Fluid and sporadic participation in CS activities. Informants often complained about the sporadic participation of their colleagues to the CS activities, explaining that a typical problem of projects launched in the CS was the gradual decrease of the participation rate over time. As it can be seen in the appendix, users explained that the first sessions were always very participated. Subsequently, while the majority of people invited to CS sessions actively manifested their interest to participate also in the following sections, as the project unfolded, sessions became less and less participated, such that teams gradually lost their heterogeneity, which, as explained above, was considered the main strength of the CS approach.

"As far as my project is concerned, I noticed that participations were not constant, or at least, the most constant were people coming from $R \& D$ or from Quality. Others were often absent, be it for work problems, be it for other reasons, it was obvious that they prioritized their own work and checked in only when they had time" (Informant 1, R\&D)

Distributed and/or residual attention to CS activities (multitasking with computer, smartphone, physical presence). Both CS users and the CS management complained that the lack of active participation and attention proven by many CS users was attributable to their unwillingness or impossibility to remain offline during CS sessions. Many informants lamented that users were unable to break from work technologies as they stepped in the CS. For instance, people came 
in and out of the sessions to answer calls or make quick interventions in other meetings scheduled at the same time. Also, while users usually avoided brining their laptops in, they often used their smartphones to answer emails or instant message about other work tasks. Thus, the ideal behavior of keeping an offline status while in the CS was often impossible to achieve and attention to CS activities was often fragmented.

"Sometimes there were problems because next to us there are meeting rooms and there were people coming in and out, and later it resulted they were also attending some other meetings, or people going out to answer calls and staying on the hallway for half an hour, or even for hours in a row (...) it's understandable and it happens to everyone but if it distracts the attention from the project activities it becomes slightly disturbing". (Informant $3, R \& D$ )

CS activities as creative improvisation (someone else -i.e., CS manager-comes in prepared)

Additionally, informants complained that CS users usually "had a hard time doing their homework" as one of our informants termed it -i.e., respecting commitments taken from one session to another, for instance doing a cost analysis for a potential product to be launched with different scenarios, or contacting customers in emergent markets to ask for feedback about desired product features. According to the managers of the space, many people came in unprepared because CS sessions were widely seen as exercises in creative improvisation where mere presence and willingness to work with others on new ideas were sufficient conditions for active participation. The organizing aspects, on the other hand, were delegated to the CS managers who had the responsibility to maximize participants' creative outputs. However, behaviors such as systematizing, supporting or validating the creative ideas generated during the CS sessions were rarely performed. As some users explained, the CS was often associated to the first phase of the development process (idea generation) and dissociated from more structured activities that belonged to the phase and gate model (see Appendix). Consequently, many users expressed their concern about the gratuitous experience provided by the CS (' $\mathrm{CS}$ as play time') as opposed to business usefulness. 
"This is really a problem, the fact that they are relying too much on us and on our organization. I feel this is sometimes also an excuse to come in less prepared (...) we are trying to get this message through to everyone who participates in CS sessions (...) Another thing I noticed is that we have an increasing number of visits to the CS, like colleagues bringing in customers and suppliers to say, hey, look at this cool place that FoodCorp developed to encourage innovation (...) It's bringing us a lot of popularity but also feels at odds with what is supposed to happen here". (Informant 11, CS Manager, R\&D)

Instrumental use of CS for impression management with external stakeholders. The interview excerpt above portrays another recurrent theme: the use of the CS with external stakeholders as a showcase, and not as a laboratory. The difference lies in the fact that clients, suppliers, bloggers, or customers were often invited by insiders to take tours of the CS and introduced to company's avant-garde approach to innovation. However, such visits were often short and rarely allowed outsiders to develop hands-on experience inside the CS. Instead, informants explained that they appeared more as public relations efforts. As explained above, if on the one hand such inappropriate use allowed the CS to gain popularity inside and outside the organization in a short period of time, it also deprived it of its original purpose to become an aggregation place for different stakeholders. In turn this limited its affordance in terms of free idea exchanges between internal and external stakeholders.

\section{Expectation - experience loop}

As already announced above, we identified a set of discrepancies between the expected and the experienced behaviors of CS users that reinforce each other in a circular effect (the loop described in the model in the figure 2 as arrows reaching across expected and experienced behaviors). Specifically, the mere existence of the CS inside the company first generated expectations in employees (i.e., generalized expectations about CS as melting pot/laboratory and expected collaborative behaviors in the CS) which were later compared with lived experiences (experienced collaborative behaviors in the CS). The contrast between the two generated new expectations for future experiences in the CS, which again resulted contrasting with respect to subsequent CS experiences, perpetuating this way the loop. 
Experienced affordances and constraints for multiplex collaboration in the CS: From boundary blurring to boundary buffering

The study of the expectation-experience loop revealed a set of consequences for how the CS was experienced in terms of affordances and constraints for internal and external boundary work, respectively. We distinguish between two boundary characteristics: permeability -i.e., extent to which boundaries regulate flow and movement of participants' knowledge and ideas and infrastructuring -i.e., extent to which boundaries align participants' different tools and methods and mobilize them towards a common goal. We show that these two boundary characteristics lead to different types of affordances and constraints for boundary work, which in turn pushed individuals to enact two different boundary work strategies: boundary blurring for internal projects and boundary buffering for projects with external stakeholders. Internally, participants perceived high levels of permeability and infrastructuring and thus felt encouraged to perform boundary blurring, on the one hand, but also felt constrained by the heterogeneity and lack of control that boundary blurring brought at the team level. With respect to external collaboration, participants perceived low levels of boundary permeability and high levels of infrastructuring, which led them to perform boundary buffering. On the one hand, they felt encouraged to perform boundary buffering and on the other, they felt threatened by the increased vulnerability that boundary buffering generated.

\section{Boundary blurring: Confirmed affordances for internal co-generation}

High boundary permeability: fluid knowledge exchanges. Users stated that their experiences with the CS were consistent with many of their initial expectations. The CS, through its possibilities in terms of plasticity, informality and centrality, promoted high boundary permeability: fluid exchanges of knowledge and ideas between the organization's business functions. For instance, employees of FoodCorp distinguished the CS experience from that of working in a 'traditional open space'. While the latter certainly allowed fluid knowledge 
exchanges among colleagues, it did not favor creativity via heterogeneity of backgrounds and expertise because people who stably worked together tended to have similar thoughts and similar mental patterns in problem solving. The CS, by contrast, was not only a think tank, but also a neutral terrain that welcomed and brought together people from different departments and encouraged them to express their thoughts and opinions fluidly and without constraints. To this purpose, informants often explained to us how the modular layout of the CS and its mobile furnishings allowed them to blur functional and hierarchical barriers of the organization and exchange knowledge freely and informally, for instance by sitting down in the CS kitchen in front of a cup of coffee, by creating new prototypes and recipes during organized cooking sessions, or by retreating in the living area of the CS to have more private conversations and resolve divergences:

"We take for granted that we are locked up in functional categories, or that the $V P$ doesn't know what the $R \& D$ researcher is doing, and vice versa. But as we moved together in this flexible space, we realized it was not exactly true. Perhaps usually we are not so mixed as we were in the CS, so we don't have the chance to let our armors down. By getting together, each of us could freely talk about his or her own reality and see whether the others understand it nor not. It's a great opportunity for fee knowledge and experience exchange, maybe this is the part I like best about the CS". (Informant 5, R\&D)

High boundary infrastructuring: common goal mobilization. Internal boundary infrastructuring refers to those heterogeneous tools and methods being mobilized within the CS to focus the collaboration on a common goal. In addition to furnishings designed to stimulate the creativity and initiative, the space offered many objects for the construction of artefacts and prototypes (for example post-its, Lego blocks, pens, colored pencils, sheets, glue, scissors, twines, etc.). Being in the collaborative space during collaborative sessions, and in particular using tools and artifacts made available by the CS, increased the perception of cohesion among users coming from different functional areas.

The informants reported feeling closer to the people within the organization with whom they worked in the CS compared to colleagues in other functional areas whom they met in other 
organizational locations (i.e., meetings, open spaces, showrooms). Additionally, they reported having more tools to navigate differences, for instance compromising about product features or development times, or eliminating differences in development approach in order to focus on the needs of the organization, rather than the needs of their own organizational departments.

"The environment (of the CS) is very different from everything else we have in FoodCorp, so it takes you out of the normal logics of the organization. It's a mix of structure and de-structure, even physically speaking, you have many configurations in the same area. This gives you more flexibility in managing projects and in bringing an individual contribution to the project. I also feel there are lots of tools to help us, like blackboards, monitors and roundtables, and then all the materials used to create something can give a lot of inputs, for sure (...). The positive side is that building a prototype in real time can teach us how to communicate better (...) focus on what the customer or the consumer need, and not on what the Marketing, the R\&D or the Finance believe it is best (...)". (Informant 7, $R \& D)$

\section{Boundary blurring: Emergent constraints of co-generation}

Although the space use was partially coherent with users' expectations in terms of affordances for internal boundary work, there were also emergent constraints that derived from the users' experiences with the CS. Specifically, informants often associated high permeability and high infrastructuring to the risk of losing control on what happened in the CS. Participants perceived as threatening the exponentially increasing heterogeneity of the knowledge, projects and interests hosted by the CS. Interestingly, we noticed that while affordances were perceived in terms of collaboration opportunities, collaborative threats were formulated in terms of CS characteristics. Two concerns were voiced: the CS was becoming a chaotic area ('a maze') and, at the same time, to avoid chaos, it was becoming a forcedly isolated space ('a cloister').

High boundary permeability: CS as maze. Since space was experienced by internal users as always moving and constantly transforming, it was also perceived as being highly heterogeneous and thus messy, disordered and dispersive. For this reason, it was compared to 'a maze'. In particular, the manifold events hosted were difficult to follow through time, such that projects became black boxes not only to those who did not directly participate, but even to 
members that could not attend meetings on a regular basis. Additionally, the fact that team compositions were always changing increased the feeling of opacity of what was going on (i.e., "the CS has much more going on than anyone can keep track of" as one of the informants termed it), and left users disoriented about who was in charge of what, as exemplified in the following excerpt:

"In my view, there is a lack of privacy and a lack of structure there (in the CS)(...) and I think because there's so much going on, people coming in and out, some having private conversations, others having a conference or working on a prototype, groups laughing, screaming, joking, someone else walking down with an important client or even the President... sometimes it's chaotic. The main problem I see is that you can't know what's going on there unless you're there, you don't know if there's some free space, what the others are doing, what projects are going on, you'd need a map to navigate that, so you always need to ask to the CS managers". (Informant 12, Quality)

High boundary infrastructuring: CS as cloister. Although it was designed as a free space to be used by anyone in the company, the CS was systematically perceived as increasingly heterogeneous and thus risking losing focus (see above the concern about CS as chaotic area). However, our informants also voiced the concern that, in order to avoid chaos, the CS was under the exclusive control of the R\&D function.

As informants explained, given the heterogeneity of backgrounds and interests around each project, it was necessary that the CS was managed, and its activities carefully planned and organized. Since the employees from the R\&D department had set up the space in an area that previously belonged to their department, they were actively managing the site and all the activities organized there. Additionally, since most CS activities were centered around product innovation topics, which were seen as " $R \& D$ people's thing”, informants explained that the CS was seen as 'R\&D's cloister' -i.e., private space.

"Normally, asking or giving an appointment is a must, actually, the rule now is that you need to call in a meeting to do something in the CS. Since there's so much usually going on, there's more and more planning behind it, it seems a bit like the $R \& D$ cloister, you always need to go through (name of CS manager) to get access, so spontaneous meetings are rarely the norm (...)" (Informant $18, R \& D$ ) 
Not only did people outside R\&D perceive the collaborative space as owned by $R \& D$, but also people working in R\&D identified the space as theirs and instrumental to achieving their work objectives. These dynamics further strengthened the identity of the space like an "R\&D cloister" and not as a common space for innovation (i.e., melting pot).

\section{Boundary buffering: Confirmed affordances for controlled co-creation}

With respect to external collaboration, participants experienced low levels of boundary permeability and high levels of boundary infrastructuring, with both affording and constraining effects. On the one hand, users felt encouraged to freely exchange knowledge with outsiders and have higher reactiveness to external events, and on the other they felt threatened by the increased vulnerability generated by external projects. This particular mix of affordances and constraints led to the strategy of boundary buffering: tearing down external boundaries to enable collective action, on the one hand, while also maintaining control on the common activities in order to direct them towards preferred courses of action, such that both competitive and collaborative boundary relations were deliberately sustained (Mørk et al., 2012, O'Mahony and Bechky, 2008). As follows, we detail the affordances and constraints of the boundary buffering strategy.

Low boundary permeability: integrated knowledge exchanges with outside. As far as open innovation is concerned, we found that the CS was associated with richer and more integrated exchanges between internal and external stakeholders. However, unlike in the case of internal collaborations where the CS tore down (i.e., blurred) internal boundaries and afforded fluid knowledge exchanges, the exchanges with external stakeholders were more structured and controlled by internal stakeholders. Specifically, organizational members maintained control over the purpose of each project, and played also a significant role in setting sub-goals and directions for external participants. Within the framework established by internal members, open innovation attempts appeared more fluid, intense and dynamic than in other settings, as 
informants explained (see also Appendix). However, boundaries were never set aside, and roles between internal and external stakeholders were never blurred, but rather 'buffered' (i.e., strategic use of boundaries to reach one's own goals and maintain distinctiveness). For instance, informants explained how they used external stakeholders such as students and panels of consumers to come up with radically new product ideas, or to perform preliminary market researches.

"I found particularly useful having students come in and work on projects. Basically we give them challenges and some structured conditions and they must come up with some radically new solutions (...) they have a fresh mindset and manage to see things than are invisible to our expert eye so they ask a lot of questions, even if some of them are easy or obvious, they make us think through things that we normally take for granted. Having also external experts that know what they are talking about because they have experience in this stuff, has been added value as well". (Informant 15, R\&D)

As shown also in the excerpt above, while external stakeholders actively participated in open innovation projects within FoodCorp, such participation was always guided by internal stakeholders who decided if and to which extent to use insights from outsiders (see also other excerpts in Appendix). Thus, while inside-outside boundaries were continuously moved during collaboration in the CS, they were also re-established as the project evolved and moved across stages, such that FoodCorp maintained wide control over development projects.

High boundary infrastructuring: reactiveness to external events. Just as in the case of internal collaboration, the modularity of the physical layout and the mobility of the space's furnishings were acknowledged by informants as useful tools for reaching creative results during work sessions with external stakeholders. There was, thus, a generalized belief that the CS made available tools and methods that encouraged a project to focus on a common goal, i.e., achieving higher reactiveness to external events such as consumer needs and structural changes in the market. As exemplified in the excerpts in Appendix, users manifested the belief that living the CS and participating in design thinking sessions - including prototyping together or coordinating to conduct market research - had afforded more consumer-awareness, and more 
user-centric solutions and greater cohesion with people outside the company. Additionally, not only did the coordination with external stakeholders focus consumer needs more effectively, but the solutions were considered more "ready to use" and therefore more "original, fun and creative" and also involved important improvements in terms of response speed to these needs (e.g., improve the time to market of development projects).

\section{Emergent constraints for boundary buffering due to controlled co-creation}

Also, in regard to external organizational boundary work, we identified constraint patterns. Specifically, informants complained that external boundary work turned out to be much more complex than expected, and thus also much more effortful. The following two constraints, CS as a showcase and CS as a silo, were associated to low boundary permeability and high infrastructuring, respectively.

Low boundary permeability: CS as showcase. Differently from what happened with internal boundary work, we found that internal members' control over projects led to a very different pattern of collaboration than envisaged initially - i.e., CS as showcase, instead of laboratory. Specifically, since internal members maintained control over boundaries, they also controlled the extent to which outsiders (i.e., clients and public opinion leaders such as food bloggers and journalists) actually experienced and used the CS for contributing to joint projects. For instance, informants often referred to critical incidents in which FoodCorp's managers brought suppliers and customers to visit the space to impress them thanks to the CS innovative aspect, and thus to convey the image of FoodCorp as an innovation pioneer, but without allowing them to get immersed in the CS activities. While most of the informants we interviewed considered the use of CS as a showcase superficial and inappropriate, they explained that it continued to be a frequently employed practice that prevented more generative and immersive activities to take place with external stakeholders:

"We continue to use it as a showroom yes, it's a way of telling others we're not just an ordinary stiff multinational, we are informal and creative because we use post-its all the time (laughs). I will confess something that is really embarrassing, 
I had to even attach fake post-its a couple of times just to show what they wanted to see”. (Informant 11, CS Manager R\&D)

High boundary infrastructuring: CS as silo. Similarly, to what happened in internal innovation projects, open innovation projects were perceived as restricted and opaque to the rest of the organization. There was little visibility about which external stakeholders entered the CS, when, and why. Even less was known about the progression and the outcomes of the projects in which externals were involved. This was also caused by the fact that external stakeholders were always invited by internal employees to participate in CS activities (see discussion of low boundary permeability above), and it never happened that a project challenge was launched by external stakeholders, as it never happened that a project team was composed by more than one or two external stakeholders. As a consequence, informants often lamented that each project with external stakeholders became a black box (or 'silo' as they termed it) about which the rest of the organization had little knowledge.

"Actually, we are not very informed about what happens in embedded projects and how many we have out there. (Name of CS manager) calls us and asks "Do you want to do some activities in the CS? We discuss together the areas in which we could do something there, perhaps others do the same. But all the other projects with internals or externals, I don't know them, actually, I don't know what people are working on in there at the moment (...) It would be a good idea to let people across the organization know what is happening there, just to break this sort of black box (...)". (Informant 20, HR)

Moreover, the access to the CS depended upon organizational approval and it required the intermediation of the CS managers. For instance, to access the CS inside FoodCorp, it was necessary for external stakeholders to have an appointment set with the space manager or with other internal employees. In addition, not only did they have to register at the reception, but an internal member of the organization had to personally pick them up at the reception desk. This procedure was deemed onerous and discouraged outsiders from using the space (see excerpts in Appendix). 


\section{Unbalanced boundary work in the CS: perceived trade-off between internal and external boundary work}

The emergent constraints to internal and external boundary work were perceived as complications that required increasing efforts and attention to both types of boundary work. Both managers and users, internals and externals argued that the CS was a 'sensitive arena' where boundary work seemed 'unbalanced'. Two elements were frequently mentioned to indicate trade-offs between internal and external boundary work: limited resources for collaborative innovation in general and need for additional time to achieve successful boundary blurring and buffering, respectively. Managers of the CS repeatedly argued that the CS was a contested space and populating it with people and projects required considerable effort from all involved parties. The fact that the space was used in ways that were not initially expected (i.e., as maze, cloister, showcase, and silo) accounted for the increasing efforts required to make the CS more congruent to initial expectations. Consequently, additional resources in terms of time and attention were deemed necessary to perform boundary work successfully internally and externally. As exemplified by the following field notes, focusing on doing internal boundary work "the right way" automatically directed resources in that direction and withdrew them from doing external boundary work. In the same way, as employees focused on external boundary work, they felt they were not able to perform internal boundary work effectively, so they preferred to focus on one at a time because of limited resources available. The trade-off perception was associated to the emergent constraints of boundary work, which increased the heterogeneity of the CS, and the complexity that had to be managed inside the CS.

"I participated in different types of sessions, with external students and internal ones, with coaches and with clients, and on different topics, not only on products. If there are external people, you are a little more open to contamination, but if we stay among ourselves in the end it is easy to fall into the same ways [...] However, when there's many of us from different departments and we're not that used to 
working together, it's better not to have also external people because then the complexity just explodes". (Informant $18, R \& D$ )

Also, informants often appeared unsatisfied about the level of progression in both internal and external boundary work. Significantly, at the end of our research project, we conducted a debriefing with the informants and asked for feedback on the findings in our grounded model. While they fully agreed with our findings and indicated internal and external boundary work efforts as a critical issue in how the CS was perceived within the organization, they also appeared convinced that conducting successful collaborative product development took significant time. For instance, they manifested their conviction that the three years since the setup of the CS marked just the beginning of a long journey made of trials and errors, in which outsiders and insiders would have learned to know each other better, built on previous successes and failures, and developed more robust and functional collaboration schemes.

"According to me, the physical space is an important aspect and it must provide a lot of support for collaboration, but the interpersonal aspects are the ones that make the difference at the end of the day. If we're not able to work out internal differences, how can we do it with important customers like (name of FoodCorp's retail customer)? Also, as we bring in a client, can we also deal with interfunctional wars successfully? These are things that we must still figure out in the next years, and I believe enthusiasm will play a huge part in making individual efforts come through". (Informant 14, R\&D)

Summarizing, we refer to unbalanced boundary work to describe the condition in which an organization attempting to perform product development through multiplex (i.e., simultaneous internal and external) collaborations experienced both internal and external boundary work as more effortful than initially expected. The acknowledgement that multiplex boundary work requires more resources leads to experience a trade-off between the ability to focus on internal boundary work and the ability to perform external boundary work.

\section{Discussion}

Our analysis, summarized in the grounded model of Figure 1, has several theoretical implications. First, we suggest that the affordances and constraints related to an organization's 
attempts to engage in both internal and external innovation can be better understood when treated together, as multiplex boundary work. Our model highlights that the factors determining the innovative performance of highly heterogeneous innovation project teams regards not only how individuals decide to leverage each type of diversity (i.e., internal and external) but also the difficulties they encounter in dealing with both simultaneously. Thus, by highlighting that configurations of diversity - be they internal or external - do not explain by themselves innovation performance, the study extends previous innovation literature that has mainly focused on the relation between structural configuration of highly diverse teams and their performance (Dvir et al., 1998, Jassawalla and Sashittal, 1999, Mannix and Neale, 2005). Adopting the theoretical lens of boundary work, the study brings to the fore the paramount role of several boundary work mechanisms related to a Collaborative Space in individuals' ability to act collaboratively in innovation projects with high diversity. As follows we comment on each mechanism.

\section{The mediation of Collaborative Spaces in expectation-experience loops regarding collaborative innovation}

The study highlights a paradoxical mechanism according to which when an organization makes available support tools to help its members face the complexities of innovation processes, if the same tools are 'associable' to generalized expectations about successful innovation, they may determine the opposite outcome by triggering in participants illusionary expectations of success that could clash with actual experiences. For instance, when the collaborative space was proposed as a generic support tool for open innovation, FoodCorp's double objective to tear down internal boundaries (i.e., cross-functional co-generation), and gain further control on external boundaries (i.e., interdependent involvement) became embedded. The image of the collaborative space as 'innovation laboratory' stimulated individuals' expectations about collaborative innovation, projecting them in a future where cross-functional and internal- 
external differences could have been easily overcome and free knowledge exchanges would have become the norm. However, we also testified the perils and illusions of such mechanism. The expectation-experience loop documented in this study indicates the likelihood that expected and experienced collaboration behaviors in complex innovation projects become contrasting because individuals underestimate the very complexity that the support tool is trying to solve. Put differently, when collaborative innovation support tools such as a collaborative space are seen as 'shortcut' for express collaboration, negative consequences may emerge because of underexplored and underestimated dynamics of actual collaboration.

In line with the socio-material perspective in boundary work (Leonardi, 2012, Orlikowski and Scott, 2008, Okhuysen and Bechky, 2009, Nicolini et al., 2012), we highlight the important link between individuals' perceptions of the material features of a space and the boundary work strategy that they decide to enact. We confirm that configurational features of collaborative spaces often emphasized by the innovation literature - in our case, centrality, modularity and plasticity - acted as triggers of expectations about successful collaboration (Bechky, 2003, Carlile, 2004, Ungureanu et al., 2018b, Koskinen, 2005, Boscherini et al., 2010). So far, the few innovation studies addressing boundary objects as support tools for innovation have either focused on their physical features (Boscherini et al., 2010) or highlighted the interpretations of boundary objects during innovation projects (Koskinen, 2005), portraying them as unambiguous tools that can be univocally set up, planed, and managed in order to maximize innovation performance (Barley, 2015). By contrast, our study goes beyond the established configurational approach. We draw attention to the ambiguous nature of collaborative spaces, by portraying them as boundary objects for open innovation and in line with a socio-material approach, we suggest that collaborative spaces often generate both affordances and constraints for collaboration. To this purpose, we emphasize that perceived material features of the CS act as a 'scaffold' (i.e., container) for individuals' expectations about complex innovation projects, 
and not as the drivers of innovation themselves (Edmondson and Harvey, 2018). We have shown that expectations about setting up a laboratory for free and fluid knowledge exchanges was opposed by other four emergent perceptions of the CS: as maze, cloister, silo and showcase. Based on these findings, we argue that using collaborative spaces as boundary objects in complex innovation projects may be less straightforward than suggested by innovation studies. For instance, instead of promptly recognizing boundary objects and using them effectively to maximize innovation outcomes (Boscherini et al., 2010, Koskinen, 2005), individuals may often engage in trial and error processes in which objects' usefulness is first approximated (i.e., lab), then may undergo conflicting perceptions (maze, cloister, silo and showcase) and become actively edited/reconfigured as the collaboration in the innovation project evolves (Carlile, 2002, Bechky, 2003, Edmondson and Harvey, 2018, Edmondson and Nembhard, 2009, Nicolini et al., 2012).

\section{Multiplex boundary work strategies in open innovation projects:}

While previous literature on innovation teams pays particular attention to team configurations, we propose an attention shift to the configurations of boundaries. A main contribution of this study is to explain how boundary work happens in innovation projects operating across what we here define as 'multiplex boundaries': collaborative configurations that allow simultaneous work on multiple boundaries having different characteristics. The study identified two boundary characteristics: boundary permeability and boundary infrastructuring and showed that the same collaborative space privileged different types of boundary configurations, according to whether individuals were involved in internal (cross-functional) projects or in projects with external stakeholders (open innovation). Specifically, internal boundaries were perceived as highly permeable and highly infrastructured while external boundaries were perceived as having low permeability and high infrastructuring. It is noteworthy that this composite boundary articulation occurred within the same physical space. Hernes (2004) talks 
about different types of boundaries that organizational members act towards and with -i.e., mental, social and physical- suggesting that affordances and constraints occur because individuals always mobilize a combination of such boundaries when they collaborate in diverse teams. For instance, one may fail to perform successful boundary work if too much attention is placed on breaking physical boundaries while social or mental boundaries remain unchanged. In our study, while internal and external projects were carried out within the same space, the same physical boundaries were perceived as having different degrees of permeability - i.e., different degrees to which they allowed free and fluid knowledge exchanges between involved parties - and in turn influenced what individuals believed they could accomplish together (i.e., boundary blurring or boundary buffering). Importantly, we have shown that simultaneous boundary spanning may increase perceived project heterogeneity and create a trade-off between participants' internal and external boundary work resources - i.e., attention and relational efforts. Too much heterogeneity, if not managed well, can inhibit creativity and efficient collaboration. For instance, being able to use the space according to one's needs is an important aspect of space-centered innovation because it takes into account the individual needs of control of the work area and the exchanges of knowledge that take place within it (Dul et al., 2011, Elsbach and Pratt, 2007). However, when heterogeneity is high, the risk is that the area becomes chaotic (maze), superficial (showroom), impenetrable (cloister) or overspecialized (silo) and the control perceived by each user decreases. The main takeaway is that different perceptions of boundary configurations (i.e., permeability and infrastructuring) may lead to different perceptions of the CS and thus to different strategies of boundary spanning. The consequence is that each strategy may require by itself more time, attention and resources than initially expected by users, such that a trade-off between the two is generated. While this study documents a trade-off between internal boundary blurring and external boundary buffering, other strategies may also be present in other contexts. For instance, a recent review 
(Langley et al., 2019) identifies multiple types of boundary management strategies, from defending one's territory, to opening up to others and up to reconfiguring boundaries through sophisticated interpersonal strategies (Faraj and Yan, 2009, Ungureanu and Bertolotti, 2018). We contribute to this literature by answering a recent call by Langley and colleagues (2019) to consider not only cases of single boundary spanning but also cases in which individuals are called to perform multiplex boundary work.

\section{Limitations, Future Directions and Managerial Implications}

This study is not without limitations. Since our study relied on a single case study in a multinational organization operating in the food industry and having a high focus on innovation, our findings have limited generalizability. We thus call for future research on simultaneous internal and external boundary work in settings that are either highly similar or different from this study (e.g., flat, project-based organizations, SMEs). We also highlight the promising direction of investigating the configuration of boundaries in open and/or crossfunctional innovation projects, rather than the configuration of the project teams itself. Future research on multiplex boundaries are thus highly welcome. In a seminal study, Mary Douglas (2003) discussed boundaries as dangerous areas of tension that are constantly pushed forward by individuals who try to reach safer harbors. We have seen that high diversity can be interpreted as both a sign of danger and as an opportunity. Future studies would need to clarify when and if high diversity always causes trade-offs between different types of boundary work. Also, given that the collaborative space in our study is still undergoing transformation and since most of our informants declared that they "needed more time and effort to make collaboration work" (informants' words), we cannot exclude the possibility of a subsequent realignment between expectations and experiences. Further longitudinal research in innovation projects could clarify if the strategies observed in FoodCorp were permanent or marked just a transition stage towards more efficient strategies of multiplex boundary work. 
In terms of managerial implications, we draw the attention to the promises, advantages and disadvantages of collaborative spaces for innovation. This topic has generated high resonance in the managerial world if we consider that demand for flexible workspace solutions from corporate clients increased by $21 \%$ in 2018 worldwide and that at the end of the same year $14 \%$ of employees at large companies used some sort of collaborative space to manage business processes (Communion Cowork, 2019). Not only do we suggest that managers must pay significant attention to potential misalignments of expectations and experiences of collaboration in complex innovation projects, but we also highlight the dangers associated to considering collaborative spaces as shortcuts for diverse team management. While we acknowledge the affordances of collaborative spaces for innovation, we also draw attention to the possible pitfall that collaborative spaces, by symbolizing freedom of exchange and informality, may generate high expectations about collaboration in diverse teams. We also draw attention to the importance of anticipating possible trade-offs between innovation projects developed through cross-functional teams only, and open innovation projects involving also external stakeholders, and suggest that ordering and prioritizing boundary work may be a safer way for organizations that use both innovation methods. We also suggest that another useful strategy for dealing with internal and external boundary work is setting thresholds of diversity in both internal and external projects. This can be implemented by designing team composition in advance and by considering everyone's commitments on other similar projects or regulating flow and movement during collaboration sessions within the collaborative space.

In sum, in line with other studies in the innovation and the boundary work literatures, we have testified an effortful process of boundary work (Edmondson and Harvey, 2018). The assumption that spanning thick internal and external boundaries simultaneously is worth the effort from team members, while highly plausible, has yet to be fully examined. To this purpose, we need to further our understanding of the contingent benefits of team member 
interactions during cross-boundary teaming. Considering both collaboration behaviors and collaborative spaces should give us a better picture of the processes that are supporting or impeding spanning multiplex boundary spanning. 
Table 1. Key aspects of data collection: informants' details

\begin{tabular}{|c|c|c|c|}
\hline $\begin{array}{l}\text { FUNCTIONAL } \\
\text { AREAS }\end{array}$ & ROLE DESCRIPTION/ MISSION IN THE CS & NFORMANTS & $\begin{array}{l}\text { YEARS I } \\
\text { THE OR }\end{array}$ \\
\hline $\begin{array}{l}\text { CS } \\
\text { MANAGERS }\end{array}$ & $\begin{array}{l}\text { Space management \& innovation project design: open } \\
\text { innovation design; collaboration process facilitation, applied } \\
\text { collaboration sessions, space design, space planning, } \\
\text { coordination of both internal and external innovation projects. }\end{array}$ & 2 (female) & $\begin{array}{l}>10(1) \\
<5(1)\end{array}$ \\
\hline HR & $\begin{array}{l}\text { Plan, manage and evaluate operations of the Human Resources } \\
\text { department, including knowledge management, talent } \\
\text { development, organizational welfare programs, etc. }\end{array}$ & $\begin{array}{l}1 \text { (female) } \\
1 \text { (male) }\end{array}$ & $>10(2)$ \\
\hline MARKETING & $\begin{array}{l}\text { Research, determine, examine and evaluate demand for new and } \\
\text { existing products, targeted campaigns and promotional } \\
\text { strategies, market research interface }\end{array}$ & 4 (male) & $\begin{array}{l}>10(3) \\
<5(1)\end{array}$ \\
\hline QUALITY & $\begin{array}{l}\text { Coordinate and manage all the quality control and prevention } \\
\text { activities of a production process, to ensure that all product } \\
\text { process meets internal and external standards }\end{array}$ & 1 (female) & $>10$ \\
\hline $\mathbf{R} \& \mathbf{D}$ & $\begin{array}{l}\text { Research and development in technological innovation related } \\
\text { to improving products and production processes or creating new } \\
\text { ones; with other functions define new product specifics and } \\
\text { follow new product industrialization; manage org. knowledge } \\
\text { for innovation }\end{array}$ & $\begin{array}{l}8 \text { (female) } \\
6 \text { (male) }\end{array}$ & $\begin{array}{l}>10(12) \\
>5(2)\end{array}$ \\
\hline SALES & $\begin{array}{l}\text { Plan, organize, direct, control and evaluate the activities of } \\
\text { companies and departments involved in commercial, industrial, } \\
\text { institutional, e-business and wholesale sales activities. }\end{array}$ & 1 (female) & $>5$ \\
\hline $\begin{array}{l}\text { EXTERNAL } \\
\text { STAKE } \\
\text { HOLDERS }\end{array}$ & $\begin{array}{l}\text { Masters' students working under supervision on specific } \\
\text { innovation challenges launched by the organization } \\
\text { Business consultants on open innovation implementation using } \\
\text { design thinking method } \\
\text { Customers (retailers) invited to contribute to specific new } \\
\text { product development projects }\end{array}$ & $\begin{array}{l}5 \text { (female) } \\
2 \text { (male) }\end{array}$ & $<1(7)$ \\
\hline
\end{tabular}

Figure 2. Data structure of the grounded model

Figure 3. A grounded model of the role of collaborative space as organizational support for internal and external boundary work in innovation projects with high diversity. 
Appendix 1. Field excerpts (i.e., interviews and observations) exemplifying the categories of the grounded model

\author{
References
}

ALLEN, T. J. 1970. Communication networks in R \& D laboratories. R\&D Management, 1, $14-21$.

AMBOS, T. C., AMBOS, B., EICH, K. J. \& PUCK, J. 2016. Imbalance and isolation: How team configurations affect global knowledge sharing. Journal of International Management, 22, 316-332.

ANCONA, D. G. \& CALDWELL, D. F. 1992. Bridging the boundary: External activity and performance in organizational teams. Administrative science quarterly, 37.

BALDWIN, C. \& VON HIPPEL, E. 2011. Modeling a paradigm shift: From producer innovation to user and open collaborative innovation. Organization Science, 22, 13991417.

BARLEY, W. C. 2015. Anticipatory work: How the need to represent knowledge across boundaries shapes work practices within them. Organization Science, 26, 1612-1628.

BECHKY, B. A. 2003. Sharing meaning across occupational communities: The transformation of understanding on a production floor. Organization Science, 14, 312-330.

BERCOVITZ, J. E. \& FELDMAN, M. P. 2007. Fishing upstream: Firm innovation strategy and university research alliances. Research policy, 36, 930-948.

BOSCHERINI, L., CHIARONI, D., CHIESA, V. \& FRATTINI, F. 2010. How to use pilot projects to implement open innovation. International Journal of Innovation Management, 14, 1065-1097.

BROWN, S. L. \& EISENHARDT, K. M. 1995. Product development: Past research, present findings, and future directions. Academy of management review, 20, 343-378.

BROWN, T. 2008. Design thinking. Harvard business review, 86, 84.

CABRAL, V. \& VAN WINDEN, W. 2016. Coworking: an analysis of coworking strategies for interaction and innovation. International Journal of Knowledge-Based Development, 7, 357.

CAPDEVILA, I. 2015. Co-working spaces and the localised dynamics of innovation in Barcelona. International Journal of Innovation Management, 19, 1540004.

CARLILE, P. R. 2002. A pragmatic view of knowledge and boundaries: Boundary objects in new product development. Organization science, 13, 442-455.

CARLILE, P. R. 2004. Transferring, translating, and transforming: An integrative framework for managing knowledge across boundaries. Organization science, 15, 555-568.

CARLILE, P. R., NICOLINI, D., LANGLEY, A. \& TSOUKAS, H. 2013. How matter matters: Objects, artifacts, and materiality in organization studies, OUP Oxford.

CHESBROUGH, H. 2003a. The logic of open innovation: managing intellectual property. California management review, 45, 33-58.

CHESBROUGH, H., VANHAVERBEKE, W. \& WEST, J. 2006. Open innovation: Researching a new paradigm, Oxford University Press on Demand.

CHESBROUGH, H. W. 2003b. Open innovation: The new imperative for creating and profiting from technology, Harvard Business Press. 
CLARK, K. B. \& WHEELWRIGHT, S. C. 1993. Managing new product and process development: text and cases.

DAHLIN, K. B., WEINGART, L. R. \& HINDS, P. J. 2005. Team diversity and information use. Academy of management journal, 48, 1107-1123.

DE VAUJANY, F.-X., DANDOY, A., GRANDAZZI, A. \& FAURE, S. 2019. Experiencing a new place as an atmosphere: A focus on tours of collaborative spaces. Scandinavian Journal of Management, 35, 101030.

DONNELLON, A. 1993. Crossfunctional teams in product development: Accomodating the structure to the process. Journal of Product Innovation Management, 10, 377-392.

DOUGHERTY, D. 1993. A practice-centered model of organizational renewal through product innovation: Strategic Management Journal, 13, 277-292 (Summer 1992). Long Range Planning, 26, 154.

DOUGLAS, M. 2003. Purity and danger: An analysis of concepts of pollution and taboo, Routledge.

DUL, J., CEYLAN, C. \& JASPERS, F. 2011. Knowledge workers' creativity and the role of the physical work environment. Human resource management, 50, 715-734.

DVIR, D., LIPOVETSKY, S., SHENHAR, A. \& TISHLER, A. 1998. In search of project classification: a non-universal approach to project success factors. Research policy, 27, 915-935.

EDMONDSON, A. C. \& HARVEY, J.-F. 2018. Cross-boundary teaming for innovation: Integrating research on teams and knowledge in organizations. Human Resource Management Review, 28, 347-360.

EDMONDSON, A. C. \& NEMBHARD, I. M. 2009. Product development and learning in project teams: The challenges are the benefits. Journal of product innovation management, 26, 123-138.

ELSBACH, K. D. \& PRATT, M. G. 2007. 4 the physical environment in organizations. The Academy of Management Annals, 1, 181-224.

EMDEN, Z., CALANTONE, R. J. \& DROGE, C. 2006. Collaborating for new product development: selecting the partner with maximum potential to create value. Journal of product innovation management, 23, 330-341.

FARAJ, S. \& YAN, A. 2009. Boundary work in knowledge teams. Journal of Applied Psychology, 94, 604.

FAYARD, A.-L. \& WEEKS, J. 2007. Photocopiers and water-coolers: The affordances of informal interaction. Organization studies, 28, 605-634.

FURNARI, S. 2014. Interstitial spaces: Microinteraction settings and the genesis of new practices between institutional fields. Academy of management review, 39, 439-462.

GANDINI, A. 2015. The rise of coworking spaces: A literature review. ephemera, 15, 193.

GARRETT, L. E., SPREITZER, G. M. \& BACEVICE, P. A. 2017. Co-constructing a sense of community at work: The emergence of community in coworking spaces. Organization Studies, 38, 821-842.

GREER, C. R. \& LEI, D. 2012. Collaborative innovation with customers: A review of the literature and suggestions for future research. International Journal of Management Reviews, 14, 63-84.

HERNES, T. 2004. Studying composite boundaries: A framework of analysis. Human relations, 57, 9-29.

HOLLAND, S., GASTON, K. \& GOMES, J. 2000. Critical success factors for cross-functional teamwork in new product development. International journal of management reviews, 2, 231-259.

HOWELL, T. \& BINGHAM, C. 2019. COWORKING SPACES. 
JASSAWALLA, A. R. \& SASHITTAL, H. C. 1999. Building collaborative cross-functional new product teams. Academy of Management Perspectives, 13, 50-63.

KELlOGG, K. C., ORLIKOWSKI, W. J. \& YATES, J. 2006. Life in the trading zone: Structuring coordination across boundaries in postbureaucratic organizations. Organization Science, 17, 22-44.

KIESLER, S. \& CUMMINGS, J. N. 2002. What do we know about proximity and distance in work groups? A legacy of research. Distributed work, 1, 57-80.

KOSKINEN, K. U. 2005. Metaphoric boundary objects as co-ordinating mechanisms in the knowledge sharing of innovation processes. European Journal of Innovation Management, 8, 323-335.

LANGLEY, A., LINDBERG, K., MØRK, B. E., NICOLINI, D., RAVIOLA, E. \& WALTER, L. 2019. Boundary Work among Groups, Occupations, and Organizations: From Cartography to Process. Academy of Management Annals, 13, 704-736.

LEONARDI, P. M. 2012. Materiality, sociomateriality, and socio-technical systems: What do these terms mean? How are they different? Do we need them. Materiality and organizing: Social interaction in a technological world, 25.

LI, Y. \& VANHAVERBEKE, W. 2009. The effects of inter-industry and country difference in supplier relationships on pioneering innovations. Technovation, 29, 843-858.

LIFSHITZ-ASSAF, H. 2018. Dismantling knowledge boundaries at NASA: The critical role of professional identity in open innovation. Administrative science quarterly, 63, 746782.

LOVELACE, K., SHAPIRO, D. L. \& WEINGART, L. R. 2001. Maximizing cross-functional new product teams' innovativeness and constraint adherence: A conflict communications perspective. Academy of management journal, 44, 779-793.

MAJCHRZAK, A., MORE, P. H. \& FARAJ, S. 2012. Transcending knowledge differences in cross-functional teams. Organization Science, 23, 951-970.

MANNIX, E. \& NEALE, M. A. 2005. What differences make a difference? The promise and reality of diverse teams in organizations. Psychological science in the public interest, 6, 31-55.

MARTIN, X. \& SALOMON, R. 2003. Knowledge transfer capacity and its implications for the theory of the multinational corporation. Journal of International Business Studies, 34, 356-373.

MCDONOUGH III, E. F. 2000. Investigation of factors contributing to the success of crossfunctional teams. Journal of Product Innovation Management: An International Publication of the Product Development \& Management Association, 17, 221-235.

MCDONOUGH III, E. F., KAHNB, K. B. \& BARCZAKA, G. 2001. An investigation of the use of global, virtual, and colocated new product development teams. Journal of Product Innovation Management: AN INTERNATIONAL PUBLICATION OF THE PRODUCT DEVELOPMENT \& MANAGEMENT ASSOCIATION, 18, 110-120.

MEYER, K. E., MUDAMBI, R. \& NARULA, R. 2011. Multinational enterprises and local contexts: The opportunities and challenges of multiple embeddedness. Journal of management studies, 48, 235-252.

MØRK, B. E., HOHOLM, T., MAANINEN-OLSSON, E. \& AANESTAD, M. 2012. Changing practice through boundary organizing: A case from medical R\&D. Human Relations, 65, 263-288.

NICHOLSON, C. Y., COMPEAU, L. D. \& SETHI, R. 2001. The role of interpersonal liking in building trust in long-term channel relationships. Journal of the Academy of Marketing Science, 29, 3.

NICOLINI, D., MENGIS, J. \& SWAN, J. 2012. Understanding the role of objects in crossdisciplinary collaboration. Organization science, 23, 612-629. 
O'MAHONY, S. \& BECHKY, B. A. 2008. Boundary organizations: Enabling collaboration among unexpected allies. Administrative science quarterly, 53, 422-459.

OKHUYSEN, G. A. \& BECHKY, B. A. 2009. 10 Coordination in Organizations: An Integrative Perspective. Academy of Management Annals, 3, 463-502.

OKSANEN, K. \& STÅHLE, P. 2013. Physical environment as a source for innovation: investigating the attributes of innovative space. Journal of knowledge management, 17, 815-827.

ORLIKOWSKI, W. J. \& SCOTT, S. V. 2008. 10 sociomateriality: challenging the separation of technology, work and organization. The academy of management annals, 2, 433474.

PEARCE, B., HINDS, P., ALTMAN, H. T., THOMASON, B., VAERLANDER, S. \& LI, K. What Happened to My Office? The Role of Place Identity at Work. Academy of Management Proceedings, 2016. Academy of Management Briarcliff Manor, NY $10510,11983$.

SANTOS, F. M. \& EISENHARDT, K. M. 2005. Organizational boundaries and theories of organization. Organization science, 16, 491-508.

SLOWINSKI, G. \& SAGAL, M. W. 2010. Good practices in open innovation. ResearchTechnology Management, 53, 38-45.

SPAETH, S., STUERMER, M. \& VON KROGH, G. 2010. Enabling knowledge creation through outsiders: towards a push model of open innovation. International Journal of Technology Management, 52, 411-431.

SPINUZZI, C. 2012. Working alone together: Coworking as emergent collaborative activity. Journal of Business and Technical Communication, 26, 399-441.

STAM, E. 2009. Entrepreneurship, evolution and geography. Papers on economics and evolution.

STRAUSS, A. \& CORBIN, J. 1998. Basics of qualitative research techniques, Sage publications Thousand Oaks, CA.

THAMHAIN, H. J. 2003. Managing innovative R\&D teams. $R \& d$ Management, 33, 297-311.

TUSHMAN, M. L. 1978. Technical communication in R \& D laboratories: The impact of project work characteristics. Academy of Management Journal, 21, 624-645.

UNGUREANU, P. \& BERTOLOTTI, F. 2018. Building and Breaching Boundaries at Once: An Exploration of How Management Academics and Practitioners Perform Boundary Work in Executive Classrooms. Academy of Management Learning \& Education, 17, 425-452.

UNGUREANU, P., BERTOLOTTI, F., MATTARELLI, E. \& BELLESIA, F. 2018a. Making matters worse by trying to make them better? Exploring vicious circles of decision in hybrid partnerships. Organization Studies, 0170840618765575.

UNGUREANU, P., BERTOLOTTI, F., MATTARELLI, E. \& BELLESIA, F. 2019. Collaboration and identity formation in strategic interorganizational partnerships: An exploration of swift identity processes. Strategic Organization, 1476127019840148.

UNGUREANU, P., COCHIS, C., RODIGHIERO, S., BERTOLOTTI, F., MATTARELLI, E., MONTANARI, F., RINALDINI, M. \& SCAPOLAN, A. C. 2018b. Innovating onsite or coordinating online? An exploration of how knowledge practices shape the onsite and online collaboration interplay across the lifecycle of collaborative communities. CERN IdeaSquare Journal of Experimental Innovation, 2, 22-29.

UNGUREANU, P., DEBORAH, R. \& GIUSTINIANO, L. 2018c. How does organizational space help organizations cope with the challenges of ambidexterity and continue to innovate? A space reorganization experiment in a transitioning organization.

VAN MARREWIJK, A. \& YANOW, D. 2010. Organizational spaces: Rematerializing the workaday world, Edward Elgar Publishing. 
WEST, J. \& BOGERS, M. 2014. Leveraging external sources of innovation: a review of research on open innovation. Journal of Product Innovation Management, 31, 814-831. ZOTT, C., AMIT, R. \& MASSA, L. 2011. The business model: recent developments and future research. Journal of management, 37, 1019-1042.

https://communioncowork.org/statisticsandpositives 